\title{
The Impact of Drug Treatment Courts on Recovery: A Systematic Review
}

\author{
Ciska Wittouck, ${ }^{1}$ Anne Dekkers, ${ }^{2}$ Brice De Ruyver, ${ }^{1}$ \\ Wouter Vanderplasschen, ${ }^{2}$ and Freya Vander Laenen ${ }^{1}$ \\ ${ }^{1}$ Department of Penal Law and Criminology, Institute for International Research on Criminal Policy (IRCP), \\ Ghent University, 9000 Ghent, Belgium \\ ${ }^{2}$ Department of Orthopedagogics, Ghent University, 9000 Ghent, Belgium
}

Correspondence should be addressed to Ciska Wittouck; ciska.wittouck@ugent.be

Received 28 October 2012; Accepted 27 December 2012

Academic Editors: R. Apiquian, Y. Bloch, L. L. Lykouras, and W. Pigeon

Copyright (C) 2013 Ciska Wittouck et al. This is an open access article distributed under the Creative Commons Attribution License, which permits unrestricted use, distribution, and reproduction in any medium, provided the original work is properly cited.

\begin{abstract}
Introduction. Earlier reviews regarding the effectiveness of Drug Treatment Courts (DTCs) reported a reduction in reoffending and substance use. Although substance users suffer from other difficulties than drug use and judicial issues, none of these reviews focused on outcomes or effects of DTCs on drug-related life domains, such as social relationships, employment, or health. Therefor, the present paper aims to review the impact of adult DTCs on substance use and drug-related life domains. Method. Primary studies were systematically searched in Web of Knowledge. Observational and controlled evaluation studies of adult DTCs were considered eligible if substance use and/or drug-related life domains were measured. Results. Moderately positive results were found with respect to within-program substance use. Few studies used drug-related life domains as an outcome measure and most of them yielded no effects. Employment and family relations ameliorated when specific interventions were used. Discussion. DTCs yield beneficial outcomes and effects regarding within-program substance use. However, evidence regarding the impact of DTCs on post-program drug and alcohol use and on other drug-related life domains is scarce. These life domains and thus QoL possibly can be improved by DTCs if specifically targeted. Future research is warranted.
\end{abstract}

\section{Introduction}

Substance use disorders (SUDs) are important public health problems in Western countries $[1,2]$ and are often regarded as chronic relapsing disorders [3-6]. The chronicity of SUDs is illustrated by the observation that most substance users cycle repeatedly between abstinence on the one hand and relapses into active substance use on the other hand before reaching the phase of stable recovery. Sometimes stable recovery is never reached [7]. In the past, lifelong abstinence was seen as the only indicator of recovery. In recent years, however, abstinence is seen as just one indicator of recovery. A shift towards a focus on other life domains and quality of life (QoL) as indicators for recovery from SUDs has been initiated $[4,8]$. SUDs are typically associated with severe impairments in drug-related life domains such as health, wellbeing, social network, employment, and financial situation [3-6]. Difficulties in these life domains remain for several years after abstinence has been achieved, particularly in the area of employment [4]. Consequently, recovery from SUDs goes beyond abstinence, instead all associated life domains should be considered. Commitment to recovery is related to one's QoL which in its turn can be enhanced by (re)gaining and maintaining certain desired needs in life (e.g., stable housing, education and work, family, wellbeing, and stable financial situation) [9-11].

Substance users are highly prevalent in the criminal justice system [12, 13] due to substance-related offences (e.g., possession and/or consumption of drugs, driving while intoxicated and theft). Imposing judicial alternatives to imprisonment on substance using offenders contains an opportunity to divert them to community (drug) treatment services. These alternative measures are associated with improvements in drug-related life domains, next to decreases in criminal offending and substance use [14-16]. Generally, 
the initiation and maintenance of desistance from (drugrelated) crime should be accompanied by improvement in several life domains, such as social network, employment, and housing [17-19].

At court level, Drug Treatment Courts (DTCs) were introduced to divert substance using offenders to (drug) treatment services [20]. Although DTCs differ greatly with respect to, amongst others, inclusion criteria, procedures, treatment services, and treatment providers [21], some key components can be distinguished: (1) alcohol and drug treatment and rehabilitation services are present for participants, (2) a nonadversarial approach and an ongoing judicial interaction with participants, (3) frequent alcohol and drug testing, (4) rewarding or sanctioning according to participants' compliance, (5) monitoring and evaluation of program goals during multiple court hearings, and (6) partnerships between drug court, public agencies, and community-based organizations [22].

During the past decade, several reviews have been published regarding the impact of DTCs on recidivism and substance use [21, 23-28]. In general, DTCs produce moderately beneficial results regarding recidivism, both during (withinprogram) [21, 23-28] and after (post-program) [23-25, 27, 28] the DTC program. These favourable outcomes apply for both drug-specific recidivism $[25,27,28]$ and overall recidivism [21, 25-28]. However, Wilson and colleagues [28] concluded that DTCs have less impact on non-drug-related offences than on drug-related offences.

With respect to substance use, results are less homogenous. While the majority of reviewers concluded that substance use, as measured by drug tests, is to a certain extent reduced in DTC participants (within-program) [21, 23-25], Wilson and colleagues [28] found a negative effect of DTCs on substance use. In these review studies no information was available regarding post-program urinalysis results, since these tests are only mandatory administered within-program. Only Brown [21] does not explicitly state that the presented results are coming from within-program drug tests.

According to the GAO review [25], data on self-reported substance use within-program are contradictory, and selfreported substance use post-program did not significantly decrease. Mitchell and co-authors [27] also concluded that substance use did not significantly decline, but they did not distinguish drug test results from self-reported substance use nor within-program from post-program results.

None of the above-mentioned systematic reviews reported data on the effects of DTCs on drug-related life domains. Although the National Association of Drug Court Professionals [22, page 7] states that "while primarily concerned with criminal activity and alcohol and other drugs use, the drug court team also needs to consider co-occurring problems such as mental illness,..., homelessness, basic educational benefits, unemployment ..., spouse and family troubles."

Obviously, improvement in drug-related life domains plays an important role on the road to recovery and should thus be considered when evaluating DTC outcomes since these aim to reduce substance use and related criminal offending. However, previous reviews have not focused on these drug-related life domains. Therefore, the present paper aims to review the impact of DTCs on substance use and other drug-related life domains.

\section{Method}

2.1. Inclusion Criteria. Studies on adult DTCs, namely, standard "DTC", "Family Treatment Drug Court" (FTDC), "Dependency Drug Court” (DDC), "Driving Under Influence Court" (DUI), and "Driving While Intoxicated Court" (DWI) were included. FTDCs (or DDCs) and DUIs (or DWIs) are modeled on standard DTCs. The former are aimed at substance abusing parents, the latter at substance abusing drivers (especially drunk drivers). Observational or controlled evaluation studies of DTCs were considered eligible if at least one indicator of substance use and/or drug-related life domains, analogous to the subscales of the Addiction Severity Index (ASI; [29]) (namely, employment, financial situation, housing situation, physical and mental health, family and social relationships, and leisuretime activities), was reported as an outcome measure. No restrictions regarding measurement method or instruments were imposed.

2.2. Search Strategy and Study Selection. Web of Knowledge was consulted twice using the following search terms and Boolean operators up to December 31st, 2011: (1) a general search using drug court AND (evaluation OR effect ${ }^{*}$ OR outcome), and (2) a specific search using drug court AND (employment OR work OR income OR financial OR housing OR health OR family OR social OR leisure). The "title only" option was marked and the search was restricted from 1989, since the first DTC was implemented in this year [20].

The general and specific Web of Knowledge searches together generated 576 hits. After removing double hits and screening title and abstract, 61 potentially relevant papers were retrieved for more detailed evaluation. These studies were screened on meeting the inclusion criteria and subsequently 45 studies were excluded after reading the full texts due to irrelevant subject, descriptive nature, a mere focus on recidivism, or secondary analysis of previously published data. Finally, 16 studies met the inclusion criteria, which are [30-45] in the reference list of this paper.

2.3. Data Extraction. Eligible studies were independently screened by two researchers (C. Wittouck and A. Dekkers) using a checklist to extract data on the following variables: (1) author, publication data, and country where the study was conducted, (2) DTC characteristics and procedures, (3) study design and follow-up period, (4) description of intervention and control group (if present), (5) sample size and dropout rate, (6) demographic and substance use characteristics of participants, and (7) outcome variables, measurement instruments, and study findings. Due to the heterogeneity in study methodologies and the variety in data reporting, a narrative review was regarded as most appropriate. The individual study findings were grouped according to outcome measure 
and were tabulated in a separate table to facilitate comparison and discussion.

\section{Results}

3.1. Study Characteristics. Table 1 provides an overview of included studies, according to location of DTC, study design, participant characteristics, and outcome measures.

All but one study ([32], Australia) were conducted in the USA. In half of the studies males were overrepresented $(n=$ 8) $[30-32,34,35,38,39,42]$. In seven studies a larger number of female participants was present [33, 37, 40, 41, 43-45].

The average age of participants is 31,29 years, with a range from 24,37 [35] to 36,4 [45]. The participants are predominantly Caucasian (range $23 \%$ to $78 \%$ ) [32, 43], African American (range 20\% to 89\%) [30,34], or Hispanic (range $16,1 \%$ to $85,5 \%$ ) $[36,39]$.

3.2. Study Quality. Study quality was assessed using the Maryland Scientific Methods Scale (MSMS) [46] and was also based on the quality assessment criteria described in the guidance for undertaking systematic reviews [47].

About half of the included studies $(n=7)$ were randomized controlled trials (RCT) [30, 34-36, 38, 42, 43]. Three studies used a quasi-experimental design (QED) [33, 41, 44], and two studies a noncontrolled pre-post design (PPD) [32, 45]. All studies, except the study of Brewster [31], specified which data collection tools were used. Often used tools were court files, judicial databases, and interviews. Sample size was mentioned in all studies, and ranged from 30 [42] to 3672 [37]. Ten studies indicated the dropout rate in their research group(s) $[30,32,34-36,38-40,43,45]$ with a dropout rate between $1,4 \%$ [30] over $28 \%$ [34] to $75 \%$ [32].

The follow-up period in the 16 included studies differed to a large extent. Some studies carried out a follow-up measurement after a particular time post-admission $[36,38$, $41,45]$. Within these studies the follow-up period ranged from four months after baseline [45] up to three years after randomization [34]. In other studies, the outcomes were measured on several follow-up moments, both within- and post-program [30-32, 35, 39, 42, 43]. Some studies only compare post-program outcomes [33, 34, 37, 40,44].

3.3. Effects on Drug Use, Alcohol Use, and Other Drug-Related Life Domains. In Table 2 the individual study findings are displayed according to study design and outcome measure. Outcome measures were drug use, alcohol use, family and social relationships, employment and income, and mental and physical health. None of the included studies reported on housing situation or leisure-time activities as outcome measures. Five studies using a RCT [35, 36, 38, 42, 43] and one study using a QED [41] were treated as observational studies since they randomized between a standard DTC and an "enhanced" DTC. Some studies only reported on postprogram outcomes regarding drug use and family reunification but were still included in the review, since it could be assumed that all participants were drug users at baseline or risked losing parental rights at baseline $[33,34,37,40,44]$.
Substance use significantly improved over time in almost all studies, regardless of study design. With respect to other drug-related life domains, the difference in results between observational studies and studies using a comparison condition is very obvious. All observational studies, except one [35], conclude that DTC participants improved on all these drug-related life domains from pre- to post-test. These beneficial results were not found by controlled studies. Most of the latter types of studies only found favourable results for DTCs on drug and alcohol use. Only FTDCs found beneficial results regarding family and social relationships.

3.3.1. Effects on Drug Use. In the majority of the included studies $(n=10$, participants $n=2390)$ illicit drug use was an outcome measure. In the Freeman study [32], illicit drug use was measured indirectly by looking into self-reported weekly spending. Weekly spending significantly decreased while weekly legal income did not change significantly, indicating a reduction in drug use over time. In the other studies drug use was measured directly either by urine test results [30,31, 42] or self-reported data on drug use $[34,38,45]$ or both $[35,39$, 43].

Self-reported data on drug use showed positive results for DTC participants within-program [35, 43, 45], at discharge [39] and post-program [34, 35, 39, 43]. In addition, DTC participants reported significantly less illicit drug use than drug using offenders diverted to standard adjudication [34] and methamphetamine-dependent outpatients with no drug court supervision [39]. Leukefeld and colleagues [38] found that drug use decreased for all study groups. However, the study's high upgrading group performed significantly better than the drug court as usual and the low upgrading group.

Urine test results also showed beneficial outcomes for DTC participants during the DTC trajectory [39, 42, 43]. Only one study reported on urine test results after a DTC program. Specifically, Dakof and colleagues [43] found that mothers were less likely to provide a positive urine test after the DDC program ended. Deschenes et al. [30] found that about half of DTC participants as well as probationers delivered a positive drug test within-program. Significant differences between these two study groups emerged when type of drugs was considered. Probationers tested significantly more positive for cocaine and heroin, whereas drug court participants were significantly more likely to test positive for marijuana.

Not all studies concluded unanimously positive. Although both DTC study groups in the Marlowe et al. study [35] significantly improved with respect to self-reported drug problems, these results were not mirrored by the urine drug screen results. Positive urine drug screens increased, although not significantly, over time for both conditions. Most of these positive drug tests were related to cannabis use. But then, the vast majority of study participants were cannabis users at baseline. Brewster [31] found that, although the rate of positive drug tests was lower for DTC participants in comparison with probation participants, a comparable amount of participants from both study groups remained drug-free throughout the study period. Possibly, the higher 


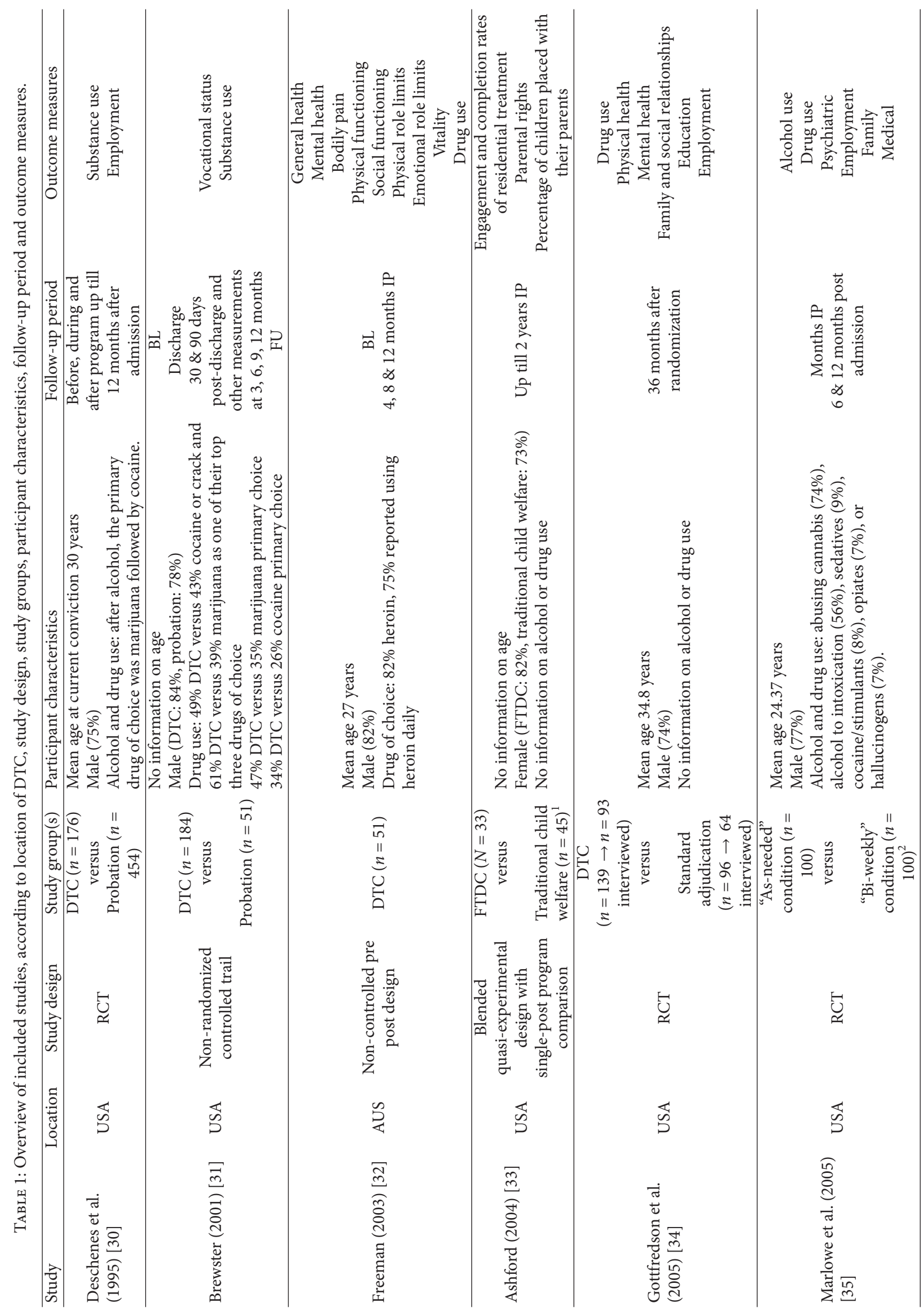




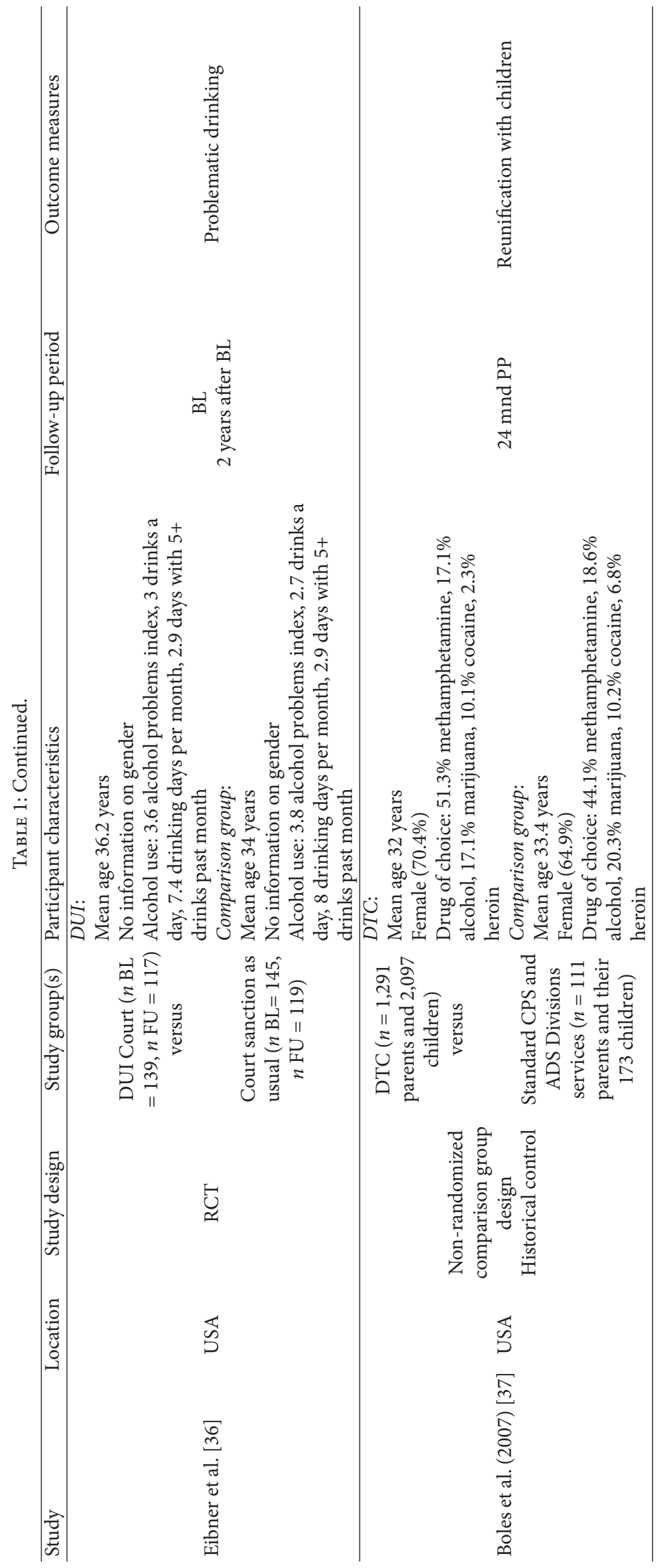




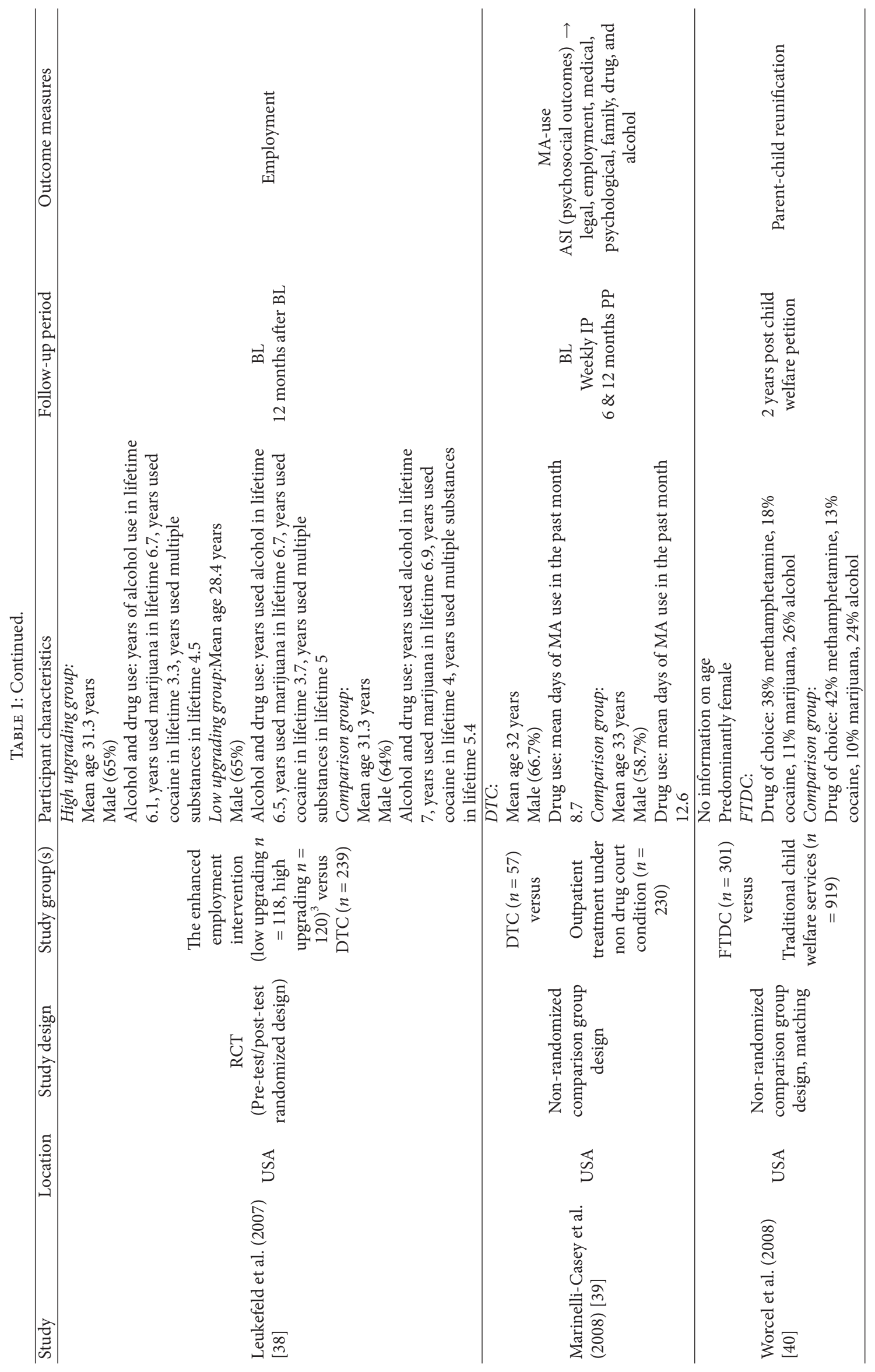




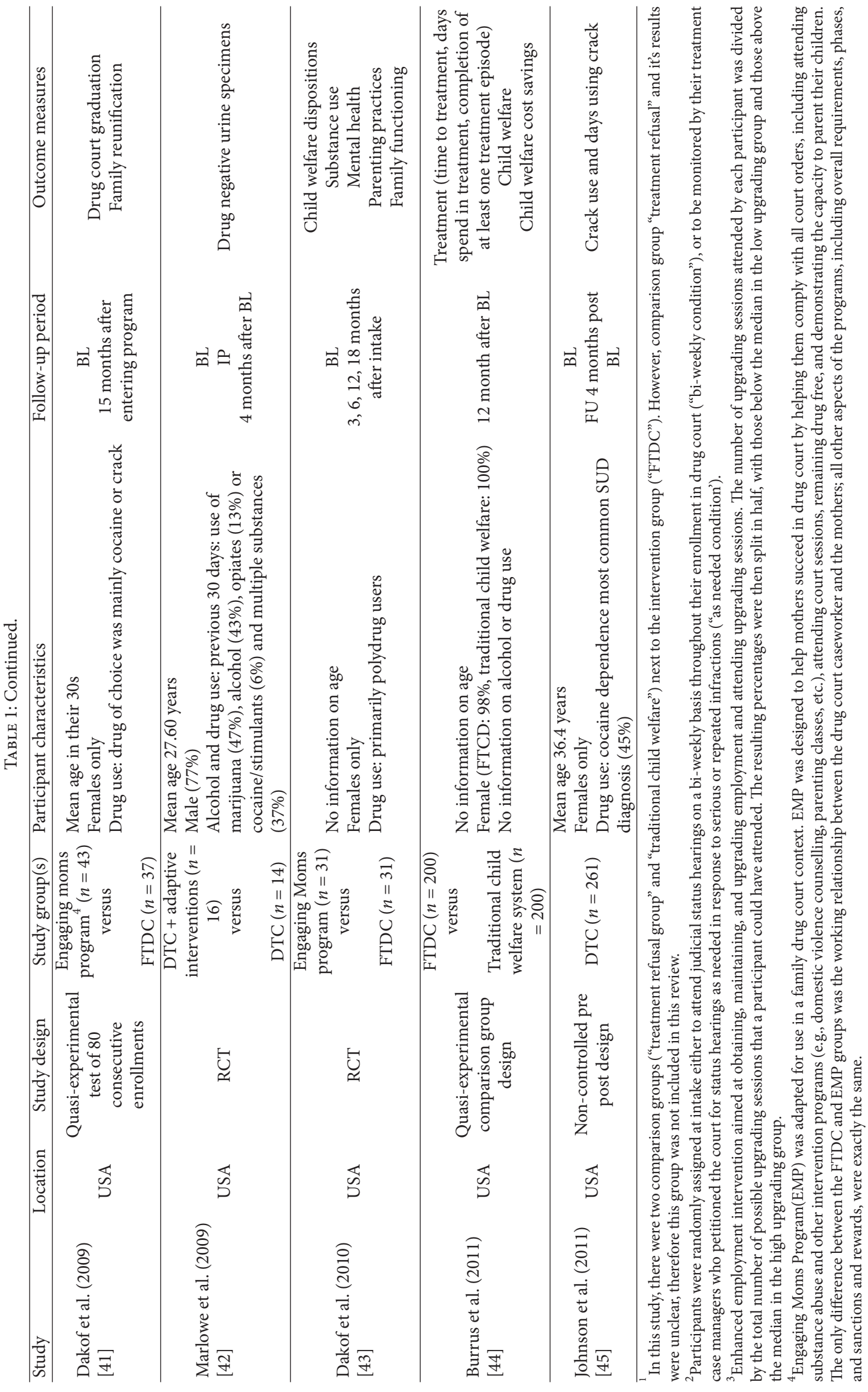


TABLE 2: Individual study findings according to study design and outcomes measure*.

\begin{tabular}{|c|c|c|c|c|c|c|c|}
\hline & Drug use & Alcohol use & $\begin{array}{l}\text { Family } \\
\text { (and social) relationships }\end{array}$ & Employment & Income & Mental health & Physical health \\
\hline \multicolumn{8}{|l|}{$\mathrm{PPD}^{1}$} \\
\hline Johnson et al. (2011) [45] & + & $\#$ & $\#$ & $\#$ & \# & $\#$ & \# \\
\hline Freeman (2003) [32] & + & $\#$ & + & $\#$ & \# & + & + \\
\hline \multicolumn{8}{|l|}{$\mathrm{RCT}^{2}$ or $\mathrm{QED}^{3}$ treated as $\mathrm{PPD}$} \\
\hline Dakof et al. (2010) [43] & + & + & + & + & & + & + \\
\hline Dakof et al. (2009) [41] & $\#$ & $\#$ & + & $\#$ & $\#$ & $\#$ & $\#$ \\
\hline Marlowe et al. (2009) [42] & + & $\#$ & $\#$ & $\#$ & \# & $\#$ & $\#$ \\
\hline Leukefeld et al. (2007) [38] & + & + & \# & + & + & \# & \# \\
\hline Eibner et al. (2006) [36] & & + & $\#$ & $\#$ & \# & $\#$ & \# \\
\hline Marlowe et al. (2005) [35] & $+(-)$ & + & $=$ & $=$ & & $=$ & + \\
\hline \multicolumn{8}{|l|}{ QED } \\
\hline Burrus et al. (2011) [44] & $\#$ & \# & + & $\#$ & \# & $\#$ & $\#$ \\
\hline Worcel et al. (2008) [40] & $\#$ & \# & + & \# & \# & $\#$ & \# \\
\hline $\begin{array}{l}\text { Marinelli-casey et al. (2008) } \\
\text { [39] }\end{array}$ & + & $=$ & $=$ & $=$ & & $=$ & $=$ \\
\hline Boles et al. (2007) [37] & $\#$ & $\#$ & + & $\#$ & \# & \# & \# \\
\hline Ashford (2004) [33] & $\#$ & $\#$ & $=$ & $\#$ & \# & $\#$ & $\#$ \\
\hline Brewster (2001) [31] & $=$ & $\#$ & $\#$ & $=$ & $\#$ & $\#$ & $\#$ \\
\hline \multicolumn{8}{|l|}{ RCT } \\
\hline Gottfredson et al. (2005) [34] & + & + & $=$ & $=$ & + & $=$ & $=$ \\
\hline Deschenes et al. (1995) [30] & + & $\#$ & $\#$ & - & $\#$ & $\#$ & $\#$ \\
\hline
\end{tabular}

amount of positive drug tests among probationers can be attributed to drug testing at irregular intervals (e.g. in case of suspicion) of drug use), while testing of DTC participants at regular intervals is standard practice.

3.3.2. Effects on Alcohol Use. Only six studies (participants $n=1419$ ) included alcohol use as an outcome measure. Eibner and colleagues [36] focused exclusively on alcohol use since they evaluated a DUI court. All six studies found that DTC participants reported significantly less alcohol use over time. DTC participants as well as outpatients with no DTC supervision, both suffering from methamphetamine dependence, reported significantly less alcohol use over time [39].

3.3.3. Effects on Family and Social Relationships. In ten of the included studies (participants $n=6207$ ) family and social relationships were used as an outcome measure. While in some studies social functioning [32], family functioning, and parenting practices $[41,43]$ of DTC participants significantly improved over time, other studies found no difference regarding family and social relationships [35].

In comparison with non-DTC methamphetaminedependent outpatients [39] and drug using offenders proc- essed through standard adjudication [34], family and social relations of DTC participants improved significantly.

Slightly more than half ( $n=6$, participants $n=5512$ ) of these ten studies evaluated FTDC $[33,37,40,41,43,44]$. Dakof and colleagues $[41,43]$ found that FTDC interventions can positively influence child welfare outcomes. Besides, at follow-up, family reunification was significantly more likely in FTDC cases than in cases processed through traditional child welfare services [37, 40,44], except in the Ashford study [33]. Children of parents managed by traditional child welfare services were significantly more likely to be allocated to out-of-home-placement [37] and to reach permanency faster [40, 44]. Ashford [33], on the other hand, found that FTDC children reached a permanency decision sooner than children in traditional child welfare services. Furthermore, time to family reunification was significantly longer for children in traditional child welfare services than children in the FTDC group [40]. In addition, Burrus and colleagues [44] found that FTDC children spent less time in nonkinship foster care. Surprisingly, Boles and colleagues [37] also found that DDC participants had a higher re-entry rate to out-ofhome care after family reunification than comparison participants. When outcomes of these re-entries were examined, however, it was found that all these comparison children 
moved to permanency, while almost one third of DDC children were subsequently reunified with their parents.

3.3.4. Effects on Employment and Income. About half of the included studies $(n=7$, participants $n=2048)$ used employment as an outcome measure, and two of these studies also reported on income. Only two studies found beneficial outcomes for DTC participants regarding employment situation. Dakof and co-authors [43] found that employment problems of mothers in DDC significantly decreased. In their evaluation of an enhanced employment intervention, Leukefeld and colleagues [38] found that high upgrading participants reported significantly more full-time employment, significantly less unemployment, and more days of working when compared to both the no-intervention and the low upgrading group. Participants in the no-intervention group worked significantly more in the past 30 days than those in the low upgrading group. In concordance with the abovementioned results, participants in the high upgrading group reported more income from a legitimate job in the past year than those in the low upgrading group. The no-intervention group did not differ from either of the upgrading groups.

In the Marlowe et al. [35] study, reported employment problems were not significantly reduced over time for participants from both DTC conditions. Furthermore, employment situation of drug court participants did not differ significantly when compared to non-drug court participants with methamphetamine dependence [39], standard adjudication [34], and probationers [31]. Deschenes and colleagues [30] even concluded that probationers were significantly more likely to be employed than drug court participants. However, during the follow-up period, DTC participants were significantly more likely than probationers to be involved in counselling and outpatient treatment sessions [30]. Although Gottfredson and co-authors [34] did not find a significant difference regarding employment situation between drug court participants and drug offenders processed through traditional adjudication, they did find the former relying on welfare significantly less than the latter, which could be due to a reduction in money spent on drug use since drug use decreased significantly in DTC participants.

3.3.5. Effects on Mental and Physical Health. In only five studies (participants $n=757$ ) the effects of drug treatment court on mental and physical health was examined. Mental health [32, 43], general health and vitality [32] of DTC participants significantly increased over time, while medical problems [35, 43], bodily pain, and emotional and physical role limits [32] of DTC participants significantly decreased over time. Marlowe and colleagues [35], however, did not find improvement for mental health and Freeman [32] found no improvement regarding physical functioning.

Furthermore, no differences were found regarding mental and physical health between DTC participants and nonDTC methamphetamine-dependent outpatients [39] nor between DCT participants and drug using offenders processed through standard adjudication [34].

\section{Discussion}

The results of the present paper show that, in general, DTCs appear to produce a decrease of illicit drug use in substance using offenders during a DTC trajectory, which was also found by earlier review studies [21, 23-25]. DTC participants, who did not reach abstinence, often moved away from more harmful substances as heroin to less harmful substances as marijuana [30]. Little information is currently available on the long-term effects of DTCs on illicit drug use. Although long-term self-report data show promising results, information from urinalysis confirming these results is lacking. Alcohol use of DTC participants also decreased. Surprisingly alcohol use was an outcome measure in only half of the included studies, given the well-established link between drug and alcohol use [48-51].

Although the importance of drug-related life domains, for example employment and housing, is recognized in the recovery and desistance literature $[9-11,14,15,17-19]$, only a small amount of DTC evaluation studies focusing on these outcomes were found. The lack of empirical data on the effects of DTCs on drug-related life domains might be explained in two ways. Or DTCs focus predominantly on substance use and drug-related crime which results in a lack of attention to other drug-related life domains. Or DTC research has not yet caught up with the state of the art on recovery, resulting in a lack of focus on these drug-related life domains. Consequently, DTC research should broaden its focus and systematically record information on DTC interventions aimed at these drug-related life domains, and study the short-term and long-term effects of DTCs on these life domains and QoL of DTC participants. Subsequently, evidence-based recommendations can be made in order to improve DTC policy and practice.

As for the studies that do focus on drug-related life domains, observational studies found beneficial results, which were not consistently demonstrated by (randomized) controlled studies. As opposed to standard adult DTCs, FTDCs do appear to positively influence child welfare outcomes (e.g., family reunification) [37, 40, 44]. Next, Leukefeld and colleagues [38] found that DTC participants who received an enhanced employment intervention aimed at obtaining, maintaining, and upgrading employment and attended sufficient sessions, had more beneficial outcomes regarding their work situation (e.g., more full-time employment and less unemployment).

Following the (moderately) positive results of DTCs on substance use, of FTDCs on child welfare outcomes and of the DTC with an enhanced employment intervention on work situation, it can be hypothesized that providing specific interventions for each of the drug-related life domains will beneficially affect these domains. Indeed, considering the chronicity of SUDs and the complexity of associated problems [3-7], one cannot expect that a mere focus on substance use as such will automatically entail improvements in other life domains. Moreover, by offering interventions specifically aimed at improving drug-related life domains, attention is given to outcomes which are reported as desired by drug users themselves. In other words, such interventions start 
from drugs users' own experiences and expectations (e.g., QoL) [52]. After all, the recovery model is a widely used and accepted approach for supporting persons with mental health and/or addiction problems, ultimately aimed at improving QoL $[9,53,54]$. When substance users experience progress in those drug-related life domains they consider important, and subsequently in their QoL, their drug use and criminal offending could be positively influenced.

No information was available regarding the effects of DTCs on housing situation or leisure-time activities, although research shows that moving away from drugusing friends and acquaintances supports the maintenance of abstinence [17] and permanent housing is associated with a reduction in recidivism $[14,15]$. In addition, non-substancerelated leisure-time activities contribute to a higher QoL [55].

Some limitations of the present paper should be addressed. First, one should be cautious when generalizing the results of the present paper. The restriction of the search strategy to peer reviewed publications could have induced publication bias, since often only favorable results are published. Although peer review also guarantees some form of quality control. Mitchell and colleagues [27, p. 69] also found that the results of published and unpublished studies on the effects of DTCs are "roughly similar." Next, only a small number of individual studies reporting on the effects of DTCs on drug use, alcohol use, and/or drug-related life domains were available. The included studies are also marked with substantial heterogeneity regarding methodology, sample size, and measurement instruments. Comparability of individual study results is further compromised since comparability between DTCs from different jurisdictions is low (e.g., inclusion criteria, procedures, treatment services, and treatment providers) [21]. Evaluations are thus very site-specific, which gives little insight into the overall effectiveness of the system [56]. In fact, a general DTC framework and general DTC theoretical underpinnings are lacking [56, 57]. Generalizability is further limited since beneficial outcomes are more prevalent in DTC graduates than in dropouts $[25,27]$, and in general about half of DTC participants drop out of the trajectory $[21,23-25]$. The dropout rate varied greatly between the included studies, and intent-to-treat analyses were not carried out or were impossible to carry out. In addition, the included studies were almost exclusively USA based. The adoption of USA DTC practices and the generalizability of USA DTC results to other countries, especially European, is problematic because of fundamental differences in the law system. Second, RCTs, which receive the highest score on the Maryland Scientific Methods Scale [46], are rare in evaluating DTC's effectiveness. In the present review less than half of the 16 included studies used a RCT, and only two of these RCTs randomly assigned participants to DTC or another kind of judicial processing. The observational and quasi-experimental studies do not allow to conclude that the observed beneficial outcomes are attributable to DTCs, since improvement due to confounding factors cannot be ruled out. Finally, to our knowledge, the longest follow-up period in DTC evaluation studies is three years [34]. Empirical data on the long-term effects of DTCs on drug-related life domains and substance use (and criminal offending) is thus lacking since studies with extended follow-up periods are non-existent.

To conclude, although one should consider the abovementioned limitations when generalizing the present paper's results, some important conclusions should be highlighted. First, through a dominant focus on substance use and criminal offending, DTCs and DTC research possibly suffer from a lack of attention and interest for other drug-related life domains and QoL of substance users. Second, these life domains can be improved as long as they are addressed. Consequently, DTC policy and practice should be adapted according to the recent findings of recovery and desistance research by focusing on improvement in drug-related life domains and by targeting these domains using specific interventions thus improving QoL of substance using offenders. In addition, each DTC trajectory should be tailored to the unique problems a DTC client faces, herewith assuring a more individual approach. As research has shown that great interpersonal variability exists between DTC participants, and that the effectiveness of DTCs differs according to these differences $[38,58,59]$. Finally, it can be expected that a decrease in substance use and criminal offending results from better life circumstances for substance users. Therefor, future research on the effectiveness of DTCs should use a more comprehensive focus and study the short-term and long-term effects of DTCs on drug-related life domains and QoL next to the effects on substance use and criminal offending, which are, after all, socially desirable outcomes [52].

\section{Acknowledgment}

This study was supported by a grant from the Belgian Science Policy Office.

\section{References}

[1] J. C. Anthony and C. Y. Chen, "Epidemiology of drug dependence," in Textbook of Substance Abuse Treatment, M. Galanter and H. D. Kleber, Eds., pp. 55-72, American Psychiatric Publishing, Arlington, Va, USA, 2004.

[2] European Monitoring Centre for Drugs and Drug Addiction (EMCDDA), "2011 Annual report on the state of the drugs problem in Europe," Tech. Rep., Office for Official Publications of the European Communities, Luxembourg, 2011.

[3] J. F. Kelly, R. Stout, W. Zywiak, and R. Schneider, "A 3-year study of addiction mutual-help group participation following intensive outpatient treatment," Alcoholism, vol. 30, no. 8, pp. 1381-1392, 2006.

[4] A. B. Laudet and W. White, "What are your priorities right now? Identifying service needs across recovery stages to inform service development," Journal of Substance Abuse Treatment, vol. 38, no. 1, pp. 51-59, 2010.

[5] R. Fiorentine and M. P. Hillhouse, "Drug treatment and 12step program participation: the additive effects of integrated recovery activities," Journal of Substance Abuse Treatment, vol. 18, no. 1, pp. 65-74, 2000.

[6] A. T. McLellan, D. C. Lewis, C. P. O’Brien, and H. D. Kleber, "Drug dependence, a chronic medical illness implications for treatment, insurance, and outcomes evaluation," Journal of the 
American Medical Association, vol. 284, no. 13, pp. 1689-1695, 2000.

[7] M. L. Dennis, C. K. Scott, R. Funk, and M. A. Foss, "The duration and correlates of addiction and treatment careers," Journal of Substance Abuse Treatment, vol. 28, no. 1, pp. 51-62, 2005.

[8] W. L. White, "Addiction recovery: its definition and conceptual boundaries," Journal of Substance Abuse Treatment, vol. 33, no. 3, pp. 229-241, 2007.

[9] A. B. Laudet, "The road to recovery: where are we going and how do we get there? Empirically driven conclusions and future directions for service development and research," Substance Use and Misuse, vol. 43, no. 12-13, pp. 2001-2020, 2008.

[10] A. B. Laudet and W. L. White, "Recovery capital as prospective predictor of sustained recovery, life satisfaction, and stress among former poly-substance users," Substance Use and Misuse, vol. 43, no. 1, pp. 27-54, 2008.

[11] A. B. Laudet, J. B. Becker, and W. L. White, "Don't wanna go through that madness no more: quality of life satisfaction as predictor of sustained remission from illicit drug misuse," Substance Use and Misuse, vol. 44, no. 2, pp. 227-252, 2009.

[12] M. D. Anglin and Y. I. Hser, "Criminal justice and the drugabusing offender: policy issues of coerced treatment," Behavioral Sciences and the Law, vol. 9, no. 3, pp. 243-267, 1991.

[13] M. Van Ooyen-Houben, "Quasi-compulsory treatment with offenders using hard drug. A study assessing the use of quasicompulsory treatment in The Netherlands," Tijdschrift Voor Criminologie, vol. 46, pp. 233-248, 2004.

[14] E. De Wree, B. De Ruyver, and L. Pauwels, "Criminal justice responses to drug offences: recidivism following the application of alternative sanctions in Belgium," Drugs, vol. 16, no. 6, pp. 550-560, 2009.

[15] E. De Wree, L. Pauwels, C. Colman, and B. de Ruyver, "Alternative sanctions for drug users: fruitless efforts or miracle solution?" Crime, Law and Social Change, vol. 52, no. 5, pp. 513-525, 2009.

[16] A. Uchtenhagen, A. Stevens, D. Berto et al., "Evaluation of therapeutic alternatives to imprisonment for drug-dependent offenders. Findings of a comparative european multi-country study," Heroin Addiction and Related Clinical Problems, vol. 10, no. 2, pp. 5-10, 2008.

[17] D. W. Best, S. Ghufran, E. Day, R. Ray, and J. Loaring, "Breaking the habit: a retrospective analysis of desistance factors among formerly problematic heroin users," Drug and Alcohol Review, vol. 27, no. 6, pp. 619-624, 2008.

[18] R. J. Sampson and J. H. Laub, "Crime and deviance over the life course: the salience of adult social bonds," American Sociological Review, vol. 55, pp. 609-627, 1990.

[19] R. D. Schroeder, P. C. Giordano, and S. A. Cernkovich, "Drug use and desistance processes," Criminology, vol. 45, no. 1, pp. 191-222, 2007.

[20] W. Huddleston and D. B. Marlowe, "Painting the current picture: a national report on drug courts and other problemsolving court programs in the United States," Tech. Rep., National Drug Court Institute, Washington, DC, USA, 2011.

[21] R. T. Brown, "Systematic review of the impact of adult drugtreatment courts," Translational Research, vol. 155, no. 6, pp. 263-274, 2010

[22] National Association of Drug Court Professionals, Defining Drug Courts: The Key Components, Office of Justice Programs, Drug Courts Program Office, Washington, DC, USA, 1997.
[23] S. Belenko, Research on Drug Courts: A Critical Review 1999 Update, The National Center on Addiction and Substance Abuse, Columbia, NY, USA, 1999.

[24] S. Belenko, Research on Drug Courts: A Critical Review 2001 Update, The National Center on Addiction and Substance Abuse, Columbia, NY, USA, 2001.

[25] Government Accountability Office (GAO), Adult Drug Courts: Evidence Indicates Recidivism Reductions and Mixed Results for Other Outcomes, United States government Accountability Office, Washington, DC, USA, 2005.

[26] D. K. Shaffer, "Looking inside the black box of drug courts: a meta-analytic review," Justice Quarterly, vol. 28, no. 3, pp. 493-521, 2011.

[27] O. Mitchell, D. B. Wilson, A. Eggers, and D. L. MacKenzie, "Assessing the effectiveness of drug courts on recidivism: a meta-analytic review of traditional and non-traditional drug courts," Journal of Criminal Justice, vol. 40, no. 1, pp. 60-71, 2012.

[28] D. B. Wilson, O. Mitchell, and D. L. MacKenzie, "A systematic review of drug court effects on recidivism," Journal of Experimental Criminology, vol. 2, no. 4, pp. 459-487, 2006.

[29] A. T. McLellan, H. Kushner, D. Metzger et al., "The fifth edition of the addiction severity index," Journal of Substance Abuse Treatment, vol. 9, no. 3, pp. 199-213, 1992.

[30] E. P. Deschenes, S. Turner, and P. W. Greenwood, "Drug court or probation? An experimental evaluation of Maricopa County's Drug Court," The Justice System Journal, vol. 18, no. 1, pp. 55-73, 1995.

[31] M. P. Brewster, "An evaluation of the chester county (PA) drug court program," Journal of Drug Issues, vol. 31, no. 1, pp. 177-206, 2001.

[32] K. Freeman, "Health and well-being outcomes for drugdependent offenders on the NSW drug court programme," Drug and Alcohol Review, vol. 22, no. 4, pp. 409-416, 2003.

[33] J. B. Ashford, "Treating substance-abusing parents: a study of the pima country family drug court approach," Juvenile and Family Court Journal, vol. 55, no. 4, pp. 27-37, 2004.

[34] D. C. Gottfredson, B. W. Kearley, S. S. Najaka, and C. M. Rocha, "The Baltimore City drug treatment court: 3-year self-report outcome study," Evaluation Review, vol. 29, no. 1, pp. 42-64, 2005.

[35] D. B. Marlowe, D. S. Festinger, K. L. Dugosh, and P. A. Lee, "Are judicial status hearings a "key component" of drug court? Six and twelve months outcomes," Drug and Alcohol Dependence, vol. 79, no. 2, pp. 145-155, 2005.

[36] C. Eibner, A. R. Morral, R. L. Pacula, and J. MacDonald, "Is the drug court model exportable? The cost-effectiveness of a driving-under-the-influence court," Journal of Substance Abuse Treatment, vol. 31, no. 1, pp. 75-85, 2006.

[37] S. M. Boles, N. K. Young, T. Moore, and S. DiPirro-Beard, "The sacramento dependency drug court: development and outcomes," Child Maltreatment, vol. 12, no. 2, pp. 161-171, 2007.

[38] C. Leukefeld, J. M. Webster, M. Staton-Tindall, and J. Duvall, "Employment and work among drug court clients: 12-month outcomes," Substance Use and Misuse, vol. 42, no. 7, pp. 1109-1126, 2007.

[39] P. Marinelli-Casey, R. Gonzales, M. Hillhouse et al., "Drug court treatment for methamphetamine dependence: treatment response and posttreatment outcomes," Journal of Substance Abuse Treatment, vol. 34, no. 2, pp. 242-248, 2008. 
[40] S. D. Worcel, C. J. Furrer, B. L. Green, S. W. M. Burrus, and M. W. Finigan, "Effects of family treatment drug courts on substance abuse and child welfare outcomes," Child Abuse Review, vol. 17, no. 6, pp. 427-443, 2008.

[41] G. A. Dakof, J. J. B. Cohen, and E. Duarte, "Increasing family reunification for substance-abusing mothers and their children: comparing two drug court interventions in Miami," Juvenile and Family Court Journal, vol. 60, no. 4, pp. 11-23, 2009.

[42] D. B. Marlowe, D. S. Festinger, P. L. Arabia, K. L. Dugosh, K. M. Benasutti, and J. R. Croft, "Adaptive interventions may optimize outcomes in drug courts: a pilot study," Current Psychiatry Reports, vol. 11, no. 5, pp. 370-376, 2009.

[43] G. A. Dakof, J. B. Cohen, C. E. Henderson et al., "A randomized pilot study of the Engaging Moms Program for family drug court," Journal of Substance Abuse Treatment, vol. 38, no. 3, pp. 263-274, 2010.

[44] S. W. M. Burrus, J. R. Mackin, and M. Finigan, "Show me the money: child welfare cost savings of a family drug court," Juvenile and Family Court Journal, vol. 62, no. 3, pp. 1-14, 2011.

[45] J. E. Johnson, C. C. O’Leary, C. W. Striley, A. B. Abdallah, S. Bradford, and L. B. Cottler, "Effects of major depression on crack use and arrests among women in drug court," Addiction, vol. 106, no. 7, pp. 1279-1286, 2011.

[46] D. E. Polkinghorne, "Language and meaning: data collection in qualitative research," Journal of Counseling Psychology, vol. 52, no. 2, pp. 137-145, 2005.

[47] K. S. Khan, G. ter Riet, J. Glanville, A. J. Sowden, and J. Kleijnen, Undertaking Systematic Reviews of Research on Effectiveness: CRD's Guidance for Those Carrying Out or commissioning Reviews, NHS Centre for Reviews and Dissemination, University of York, North Yorkshire, UK, 2nd edition, 2001.

[48] L. Burns and M. Teesson, "Alcohol use disorders comorbid with anxiety, depression and drug use disorders: findings from the Australian national survey of mental health and well being," Drug and Alcohol Dependence, vol. 68, no. 3, pp. 299-307, 2002.

[49] S. Byqvist, "Patterns of drug use among drug misusers in Sweden. Gender differences," Substance Use and Misuse, vol. 41, no. 13, pp. 1817-1835, 2006.

[50] L. Degenhardt and W. Hall, "Patterns of co-morbidity between alcohol use and other substance use in the Australian population," Drug and Alcohol Review, vol. 22, no. 1, pp. 7-13, 2003.

[51] F. S. Stinson, B. F. Grant, D. A. Dawson, W. J. Ruan, B. Huang, and T. Saha, "Comorbidity between DSM-IV alcohol and specific drug use disorders in the United States: results from the national epidemiologic survey on alcohol and related conditions," Drug and Alcohol Dependence, vol. 80, no. 1, pp. 105-116, 2005.

[52] J. De Maeyer, W. Vanderplasschen, and E. Broekaert, "Exploratory study on drug Users' perspectives on quality of life: more than health-related quality of life?" Social Indicators Research, vol. 90, no. 1, pp. 107-126, 2009.

[53] M. Farkas, "The vision of recovery today: what it is and what it means for services," World Psychiatry, vol. 6, no. 2, pp. 68-74, 2007.

[54] C. Gagne, W. White, and W. A. Anthony, "Recovery: a common vision for the fields of mental health and addictions," Psychiatric Rehabilitation Journal, vol. 31, no. 1, pp. 32-37, 2007.

[55] C. D. Hood, "Women in recovery from alcoholism: the place of leisure," Leisure Sciences, vol. 25, no. 1, pp. 51-79, 2003.

[56] E. Slinger and R. Roesch, "Problem-solving courts in Canada: a review and a call for empirically-based evaluation methods,"
International Journal of Law and Psychiatry, vol. 33, no. 4, pp. 258-264, 2010.

[57] J. B. Stinchcomb, "Drug courts: conceptual foundation, empirical findings, and policy implications," Drugs, vol. 17, no. 2, pp. 148-167, 2010.

[58] D. DeMatteo, D. B. Marlowe, D. S. Festinger, and P. L. Arabia, "Outcome trajectories in drug court: do all participants have serious drug problems?" Criminal Justice and Behavior, vol. 36, no. 4, pp. 354-368, 2009.

[59] T. F. Garrity, S. H. Prewitt, M. Joosen, M. S. Tindall, J. M. Webster, and C. G. Leukefeld, "Baseline subjective stress predicts 1year outcomes among drug court clients," International Journal of Offender Therapy and Comparative Criminology, vol. 52, no. 3, pp. 346-357, 2008. 


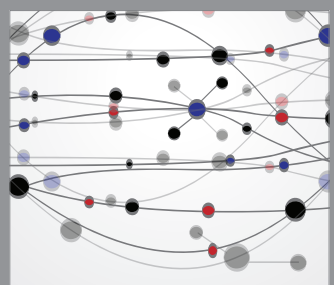

The Scientific World Journal
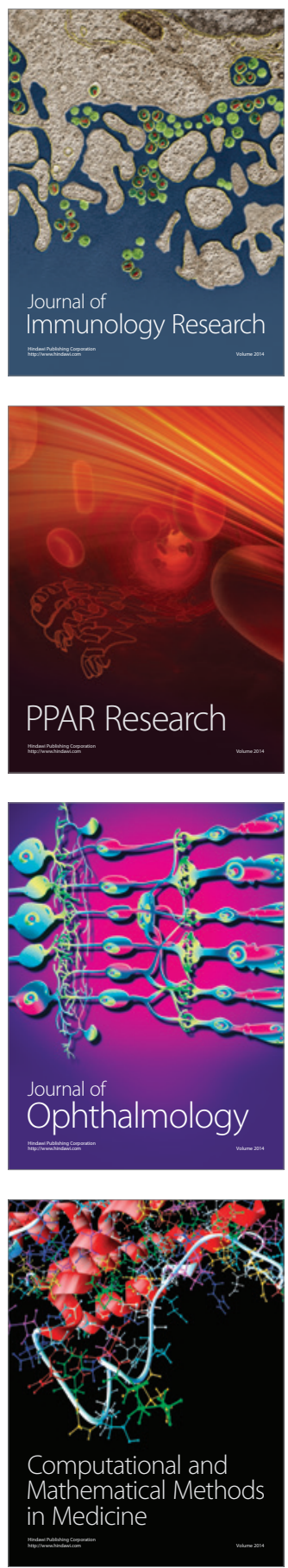

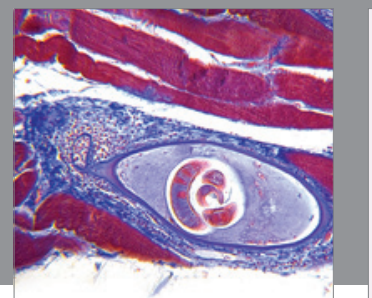

Gastroenterology

Research and Practice
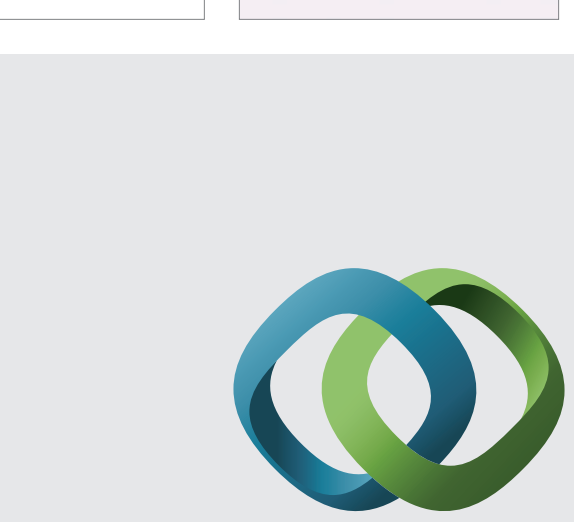

\section{Hindawi}

Submit your manuscripts at

http://www.hindawi.com
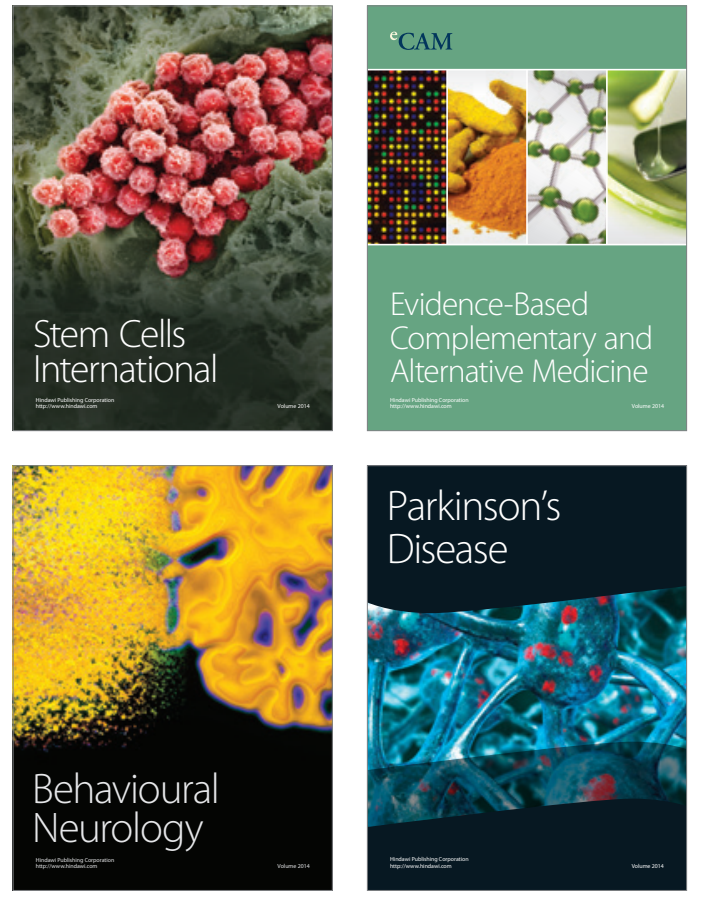
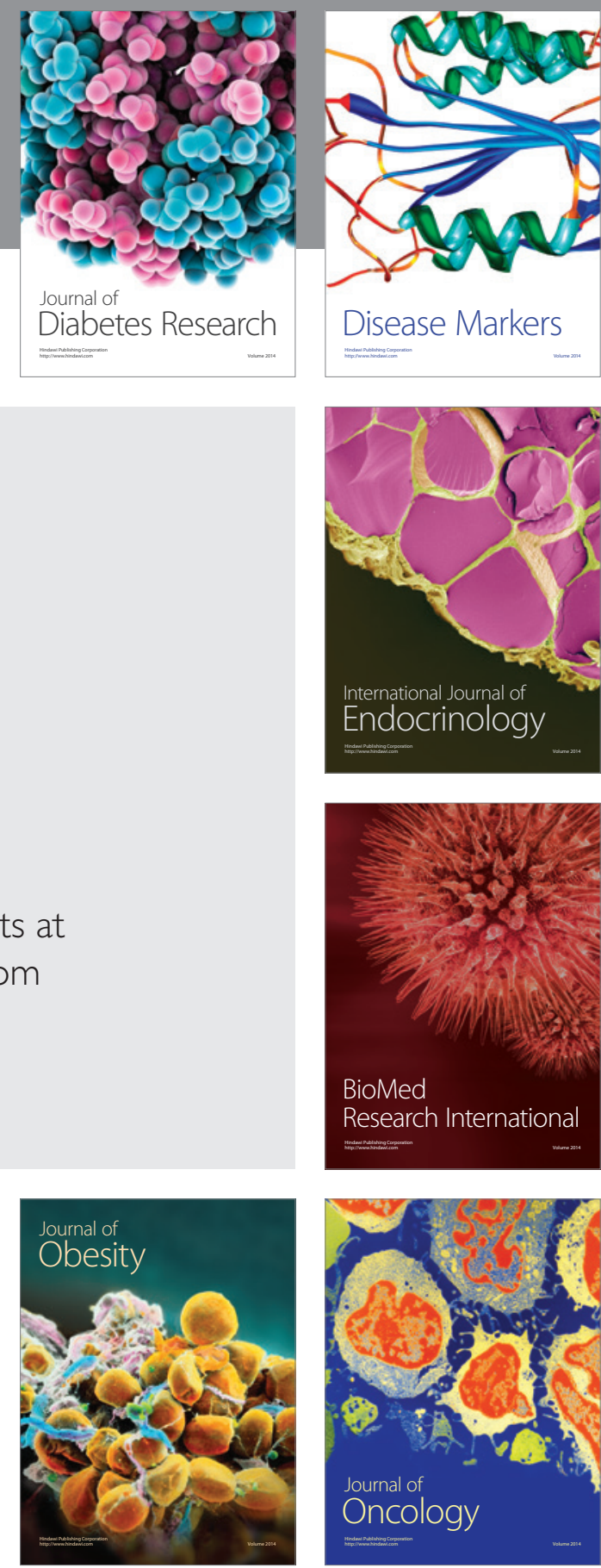

Disease Markers
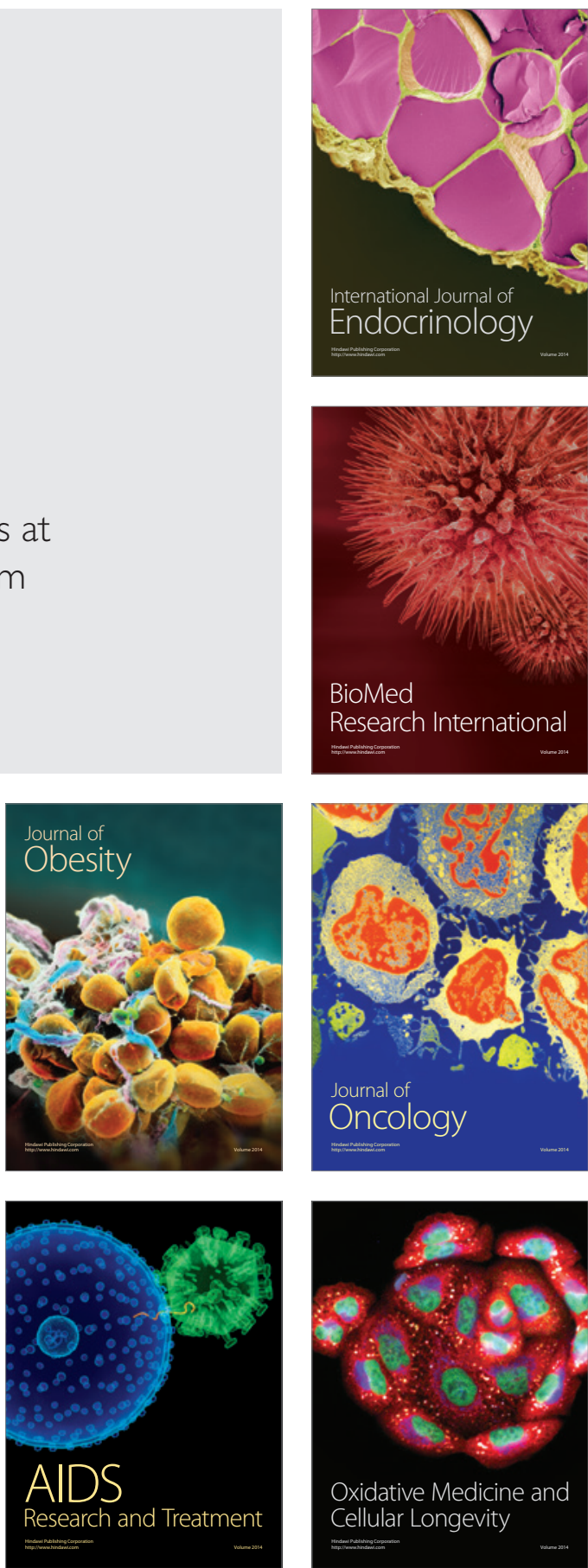